\title{
Mulheres e Desenvolvimento de Jogos: essa conjunção já existe?
}

\author{
Mariana Michels Fontoura $^{1}$, Leander de Oliveira ${ }^{1}$, Marília A. Amaral ${ }^{12}$ \\ ${ }^{1}$ Programa de Pós-graduação em Tecnologia e Sociedade (PPGTE) - Universidade \\ Tecnológica Federal do Paraná (UTFPR) - Curitiba - PR - Brasil \\ ${ }^{2}$ Departamento Acadêmico de Informática (DAINF) - Universidade Tecnológica \\ Federal do Paraná (UTFPR) - Curitiba - PR - Brasil \\ marimfontoura@gmail.com, leanderdeoliveira@gmail.com, \\ mariliaa@utfpr.edu.br
}

\begin{abstract}
Which issues and barriers do female game developers have in Brazil? This article intend to analyze mechanisms that distance women from game development. It presents a bibliographic analysis to discuss these issues and understand the involvement of women in the game development process.

Resumo. Quais barreiras encontram as mulheres desenvolvedoras de jogos no Brasil? Ao longo deste artigo pretende-se analisar alguns mecanismos que afastam mulheres das áreas de desenvolvimento de jogos. Será apresentada uma análise bibliográfica afim de discutir estas questões e compreender como as mulheres estão envolvidas no processo de desenvolvimento de jogos.
\end{abstract}

\section{Traçando Caminhos: mulheres, jogos e identidades}

Jogos online têm se tornado cada vez mais populares ao redor do mundo, e o Brasil não é exceção. Este mercado, por contar atualmente com um grande público, tem bastante movimento de mercado. Conforme informações publicadas no site da companhia Newzoo [Newzoo, 2017], a receita gerada na América Latina foi de 4,4 bilhões de dólares, e o Brasil teve a $2^{\mathrm{a}}$ maior receita entre estes países, com um total de 1,3 bilhões. Por mais que diversos desdobramentos nesta área já tenham acontecido, desenvolvedores de jogos no Brasil ainda têm dificuldades para inserir seus produtos no mercado competitivo internacional, que atualmente é dominado pela China e Estados Unidos, com receitas de mais de 25 bilhões cada [Newzoo, 2017]. Apesar de ser um mercado em grande movimento, a área da tecnologia é um ambiente tido como de domínio masculino e, por consequência, a participação das mulheres não acontece em equidade [Wajcman, 2004]. Essa herança histórica e cultural ainda interfere no modo como mulheres são tratadas em determinadas áreas associadas à tecnologia. Desta forma, ser desenvolvedora de jogos envolve ultrapassar barreiras para ocupar esta posição, exigindo a atuação em uma área que não lhe é socialmente e culturalmente esperada.

Mulheres têm tido um papel coadjuvante na produção de jogos. Segundo censo da Industria Brasileira de Jogos Digitais [Fleury et al. 2014, p. 40], em 2014 com 129 empresas brasileiras de desenvolvimento de jogos, apenas 15\% eram mulheres entre os trabalhadores. Essa diferença que se apresenta no cenário da produção de jogos é um reflexo das próprias hierarquias de relações de gênero existentes nas áreas de tecnologia, dentre as quais estão a eletrônica e a computação, áreas originárias do 
videogame [Rodrigues, 2014, p. 40]. Segundo Wajcman [2004, p.15], o estereótipo sexual (sex-stereotyping) da tecnologia leva a uma relutância das mulheres em entrar na área por esta ser percebida como uma atividade apropriada somente aos homens. Dentro desta perspectiva, para se inserir neste meio, a mulher se vê abandonando a própria feminilidade, e por consequência, parte de sua identidade como mulher. Maria Luiza P. Arantes [2016] trouxe em seu texto a ideia de uma universalização das masculinidades, em que o gênero assume um papel hierárquico e fortalece desigualdades entre as noções de feminino e masculino. A partir do momento em que estas noções são entendidas também no ambiente digital, elas passam a influenciar a produção de tecnologias, sendo a própria participação ativa neste ambiente definida dentro dessa relação hierárquica.

Entende-se que um dos mecanismos que também afasta as mulheres destas áreas de trabalho é a própria educação generificada, que direciona mulheres e homens para áreas pré-determinadas [Wajcman, 2004, p. 14]. Outro mecanismo importante encontrase na compreensão do masculino como norma, e a partir do qual é caracterizado o seu outro, neste caso, o feminino [Rodrigues, 2014, p. 38]. Esse processo exige definir o que é homem para se conceituar o que é mulher, e assim este é posicionado como 'norma' e seu outro como "fora da norma”, criando um caráter hierárquico entre estas identidades [Butler, 2017]. Neste texto, esta problematização consiste em perceber uma hegemonia masculina nos espaços da tecnologia, generificando a área e seus artefatos. Por meio desta reflexão entende-se que as produções e artefatos acabam sendo pensadas por e para homens, excluindo ou dificultando a entrada de mulheres nestes processos.

Dentro deste contexto, foram criadas no país, iniciativas que promovem discussões sobre tecnologia e suas apropriações voltadas para mulheres. Os autores Maciel e Bim [2016] apresentam algumas iniciativas, dentre elas o Meninas Também Jogam $^{1}$, projeto que busca estimulando e desmistificando a participação de mulheres no mercado de TI e de jogos através de palestras motivacionais e cursos gratuitos de Game Design, Ilustração e Programação de Games.

No caminho destas reflexões, considerando a tecnologia como artefato social e cultural carregada de valores e lutas, o presente artigo pretende desenvolver uma busca sistemática de publicações no sentido de compreender as pesquisas que tem discutido a participação da mulher no desenvolvimento de jogos.

\section{Revisão de Literatura: desenvolvimento de jogos por mulheres}

Na pesquisa de referências sobre estudos que abordem a questão de mulheres no processo de desenvolvimento de jogos, foi desenvolvida uma busca sistemática de publicações nas bases da ACM e IEEE e também nos anais dos eventos WIT e SBGames, importantes bases na área da computação (ACM e IEEE), computação e gênero (WIT) e de jogos (SBGames). A procura foi feita utilizando palavras-chave em inglês (games; developer; women) e em português (mulheres; desenvolvedoras; jogos). Após a busca, foi feita a leitura dos títulos e, se estes estivessem relacionados com a pesquisa, a leitura dos resumos e abstracts, para definir quais artigos entrariam na revisão.

1 Mais informações em <http://meninas.sbc.org.br/index.php/portfolio/meninas-tambem-jogam/> 
Os anais da SBGames apresentam uma divisão por sites, de acordo com cada edição do evento. Foi utilizado um recorte de 2011 a 2017, o que retornou apenas um artigo relacionado a pesquisa. Em relação ao WIT, devido ao evento receber publicações somente a partir do ano de 2016, foram buscadas nos anais de 2016 e 2017 as mesmas palavras-chave dos demais repositórios, não retornando trabalhos que tratem da temática desta pesquisa. No repositório da ACM, foram analisados os primeiros 120 artigos retornados pela busca das palavras-chave, já que a partir do $60^{\circ}$ resultado os títulos começaram a se duplicar e a não apresentar relação com os termos buscados. No repositório da IEEE foram encontrados somente 3 artigos, dentre os quais apenas um possui relação com a temática. Na Tabela 1 são representados os resultados encontrados nesta busca.

Tabela 1. Publicações

\begin{tabular}{|c|c|c|c|}
\hline Evento & Título & Autores & Resumo \\
\hline $\begin{array}{l}\text { SBGames } \\
2017\end{array}$ & $\begin{array}{l}\text { A Representatividade } \\
\text { das Mulheres nos } \\
\text { Games }\end{array}$ & $\begin{array}{l}\text { Paula } \\
\text { Casagrande } \\
\text { Bristot; Eliane } \\
\text { Pozzebon; } \\
\text { Luciana Bolan } \\
\text { Frigo }\end{array}$ & $\begin{array}{l}\text { Discute os fatores que levaram a falta de } \\
\text { representatividade das mulheres nos games, e } \\
\text { reconhecimento da identidade gamer. O texto } \\
\text { não se aprofunda na questão das } \\
\text { desenvolvedoras, mas passa rapidamente sobre o } \\
\text { tópico de que tanto enquanto jogadora, como } \\
\text { desenvolvedora ou personagem, as mulheres } \\
\text { fazem parte deste universo, mas ainda lutam por } \\
\text { reconhecimento dentro dos jogos. }\end{array}$ \\
\hline $\begin{array}{l}\text { IEEE } \\
2013\end{array}$ & $\begin{array}{l}\text { Female game } \\
\text { developers wanted } \\
\text { Low pay, long hours, } \\
\text { inflexible work } \\
\text { environments }\end{array}$ & $\begin{array}{l}\text { Penelope } \\
\text { Sweetser; Peta } \\
\text { Wyeth; Nicole } \\
\text { McMahon; } \\
\text { Daniel Johnson }\end{array}$ & $\begin{array}{l}\text { Afirma que na época metade dos jogadores eram } \\
\text { mulheres, mas representavam uma pequena } \\
\text { proporção entre pessoas que desenvolvem jogos. } \\
\text { Este artigo investiga as barreiras que impedem } \\
\text { mulheres de entrarem na indústria de games, e } \\
\text { soluções para atraí-las para esta indústria. }\end{array}$ \\
\hline $\begin{array}{l}\text { ACM } \\
2017\end{array}$ & $\begin{array}{l}\text { Understanding } \\
\text { Gaming Perceptions } \\
\text { and Experiences in a } \\
\text { Women's College } \\
\text { Community }\end{array}$ & $\begin{array}{l}\text { Orit Shaer; } \\
\text { Lauren } \\
\text { Westendorf; } \\
\text { Nicholas A. } \\
\text { Knouf; Claudia } \\
\text { Pederson }\end{array}$ & $\begin{array}{l}\text { Recentes tendências na diversificação de games } \\
\text { mostram que mulheres são um público } \\
\text { significativo de consumidoras e produtoras de } \\
\text { jogos. Neste artigo foram traçadas perspectivas } \\
\text { de IHC feminista para ampliar o conhecimento } \\
\text { sobre problemas em jogos relacionados } \\
\text { especificamente à mulher. }\end{array}$ \\
\hline $\begin{array}{l}\text { ACM } \\
2014\end{array}$ & $\begin{array}{l}\text { Sexism in the } \\
\text { circuitry: female } \\
\text { participation in male- } \\
\text { dominated popular } \\
\text { computer culture }\end{array}$ & $\begin{array}{l}\text { Michael James } \\
\text { Heron; Pauline } \\
\text { Belford; Ayse } \\
\text { Goker }\end{array}$ & $\begin{array}{l}\text { Os autores discutem neste artigo sexismo e } \\
\text { misoginia na cultura dos videogames, através de } \\
\text { dois exemplos de difamação de mulheres em } \\
\text { jogo e de assédio cyber-mob, como os casos de } \\
\text { Anita Sarkeesian e da desenvolvedora Zoe } \\
\text { Quinn. }\end{array}$ \\
\hline $\begin{array}{l}\text { ACM } \\
2011\end{array}$ & $\begin{array}{l}\text { Women Build } \\
\text { Games, Seriously }\end{array}$ & $\begin{array}{l}\text { Elizabeth } \\
\text { Sweedyk }\end{array}$ & $\begin{array}{l}\text { A autora discute a utilização de jogos no } \\
\text { processo de envolvimento de mulheres na área } \\
\text { da computação. Neste processo ela aponta que } \\
\text { algumas mulheres se sentem em desvantagem, } \\
\text { devido a não familiaridade com os jogos. }\end{array}$ \\
\hline $\begin{array}{l}\text { ACM } \\
2007\end{array}$ & $\begin{array}{l}\text { A Game Design } \\
\text { Methodology to } \\
\text { Incorporate Social } \\
\text { Activist Themes }\end{array}$ & $\begin{array}{l}\text { Mary Flanagan; } \\
\text { Helen } \\
\text { Nissenbaum }\end{array}$ & $\begin{array}{l}\text { As autoras debatem metodologias para o } \\
\text { envolvimento de temas de ativismo social na } \\
\text { criação de jogos. No decorrer do texto são } \\
\text { apresentados alguns dados que demonstram a } \\
\text { baixa participação de mulheres nos processos de } \\
\text { desenvolvimento de jogos. }\end{array}$ \\
\hline
\end{tabular}

Estes artigos, de forma geral, abordam a questão da falta de mulheres no 
universo dos jogos, alguns apontando hostilidades direcionadas à mulher, outros barreiras e soluções dentro deste processo. Após a análise dos dados ficou perceptível a pequena quantidade de trabalhos que abordam o tema das mulheres desenvolvedoras de jogos, apresentando uma situação ainda menos favorável no contexto brasileiro, resultando deste levantamento somente uma publicação que tenha ligação mais forte com a temática [Bristot et al., 2017]. Desta forma, esta revisão se torna necessária também para apontar a falta de pesquisas com este enfoque, dentro e fora do contexto nacional.

\section{Qual é o Cenário?}

A trajetória de mulheres no desenvolvimento de jogos ainda é conturbada devido a uma porção de fatores que promovem a sua não participação em áreas voltadas à tecnologia. A questão histórica que envolve essa concepção está ligada aos processos de estereotipação de gênero que as atividades sofrem, tornando alguns ambientes inóspitos para algumas pessoas. Percebe-se que essas barreiras históricas e culturais fomentam a criação de iniciativas com o potencial de atuar no despertar de interesse de jovens estudantes por estas áreas, além de aumentar a motivação de mulheres que já atuam neste meio.

Nas revisões de publicações, além dos dados trazidos por trabalhos como o de Maciel e Bim (2016) sobre iniciativas de mulheres, foi encontrado um cenário que demonstra a existência de algumas frentes que buscam mudanças neste quadro. Estas ações podem ser compreendidas como um movimento feminista na área, que busca desestabilizar hegemonias e repensar os/as sujeitos/as que a constroem, processo que reflete tanto nas relações sociais e identidades, quanto nos artefatos e possíveis apropriações futuras.

\section{Referências}

Arantes, Maria Luiza Petranski. Sexismo nos Campos de Justiça: O Posicionamento de Marca Interferindo na Jogabilidade de League of Legends. 2016. 76f. Monografia (Trabalho de Conclusão de Curso) - Publicidade e Propaganda, Universidade Federal do Paraná, 2016.

Bristot, Paula C.; Pozzebon, Eliane; Frigo, Luciana B.. A Representatividade das Mulheres nos Games. Anais do XVI SBGames, Curitiba. 2017.

Butler, Judith. Problemas de gênero: feminismo e subversão da identidade. 13 ed. Tradução de Renato Aguiar. Rio de janeiro: Civilização Brasileira, 2017.

Fleury, Afonso; Sakuda, Luiz Ojima; Cordeiro, José H. D. $1^{\circ}$ Censo da Industria Brasileira de Jogos Digitais. Pesquisa do GEDIGames, NPGT, Escola Politécnica, USP. São Paulo. 2014.

Maciel, Cristiano; Bim, Sílvia Amélia. Programa Meninas Digitais - ações para divulgar a Computação para meninas do ensino médio. Computer on the Beach 2016. $7^{\text {a }}$ Edição, Florianópolis. Anais do Computer on the Beach. Disponivel em: <https://siaiap32.univali.br/seer/index.php/acotb/issue/view/439>.

Newzoo. Global Games Market Report. Amsterdã, 2017. Disponível em: $<$ https://newzoo.com/resources>. Acesso em 04 abril, 2018. 
Rodrigues, Letícia. Um estudo em representações gráficas nos jogos eletrônicos na perspectiva das relações de gênero: os tipos de feminilidade em League of Legends. 2014. 171 f. Trabalho de Conclusão de Curso (Graduação) - Universidade Tecnológica Federal do Paraná, Curitiba, 2014.

Wajcman, Judy. TechnoFeminism. Oxford: Marston Book Services Limited, 2004. 156 p. 